\title{
Managing mercury exposure in northern Canadian communities
}

\author{
Catherine McLean Pirkle PhD, Gina Muckle PhD, Melanie Lemire PhD
}

$\mathrm{M}$ ercury is a toxic metal that can cause deleterious neurologic effects at any age, although the fetus is especially at risk. ${ }^{1}$ Most Canadians are exposed to mercury through diet, specifically fish consumption. ${ }^{2} \mathrm{Sev}$ eral Canadian clinical guidance publications assist health professionals in recognizing clinically important mercury levels and appropriate interventions..$^{2-4}$ However, the information is poorly adapted to the circumstances of geographically remote northern communities, for whom mercury exposure may be greater. ${ }^{5}$

In this article, we review the literature on the effects of mercury exposure and its management, in the context of other challenges that northern primarily indigenous - Canadian communities face. These challenges include highly prevalent food insecurity associated with a rapid transition toward store-bought foods and decreasing access to local natural resources. ${ }^{6,7} \mathrm{We}$ also provide guidance for promoting patient health, especially during pregnancy, while addressing mercury exposure in at-risk populations. Our search strategy is summarized in Box $1 .^{8-10}$ The principles and suggestions in this paper apply directly to practitioners working in northern Canadian communities, where wild foods are important dietary components. They are more broadly applicable to practitioners working with patients or in communities with high fish consumption.

\section{How do people in northern Canada become exposed to mercury?}

Some local ecosystems in northern Canada and the wild foods that come from those ecosystems are contaminated by mercury, which increases the risk of exposure. Despite limited industrial activity, ${ }^{11}$ the environmental burden of mercury may be greater in northern Canada than further south because mercury released to the atmosphere and oceans, primarily from coal combustion and small-scale gold mining in emerging economies, is subject to long-distance transport and accumulation at the higher latitudes. ${ }^{12}$ Moreover, wild foods from recently impounded reservoirs (e.g., hydroelectric reservoirs in Quebec, Manitoba and Labrador) can contain very high mercury concentrations because of the mobilization of naturally occurring mercury in soils into aquatic ecosystems. ${ }^{13}$ Industrial activities in the Athabasca oil sands region also appear to be releasing mercury into the surrounding environment. ${ }^{14}$

Mercury's three common forms are elemental, inorganic and methylmercury. Methylmercury is encountered through diet, and because of its ubiquity, it is of most concern to health professionals. ${ }^{12}$ When either elemental or inorganic mercury enters aquatic ecosystems, it is transformed into methylmercury by aquatic microbial activity. Methylmercury bioaccumulates over time in the flesh and organs of living organisms and is biomagnified in top predators of aquatic food webs, such as predatory fish and marine mammals. When humans consume these fish and mammals, they become exposed to high concentrations of methylmercury. ${ }^{12}$ Unless otherwise noted, we dicuss dietary exposure and are therefore referring to methylmercury with the word mercury.

Dietary mercury is absorbed efficiently by the gut, distributed throughout the body and actively transported through blood-brain and bloodplacental barriers. ${ }^{12}$ Mercury accumulation is greater in the fetus than in the mother: concentrations are about 1.5 times higher in umbilical cord blood samples than in maternal blood samples at
Competing interests: Catherine Pirkle received funds from the Lepercq Charitable Foundation to create a mobile application for Bermuda residents about mercury concentrations in local fish species. No other competing interests were declared.

This article has been peer reviewed.

Correspondence to: Catherine Pirkle, cmpirkle@hawaii.edu

CMAJ 2016. DOI:10.1503 /cmaj.151138

\section{- Ker points}

- Many northern communities in Canada are deeply connected to the sea, rivers and lakes for food, medicine, livelihood and identity, but they are often exposed to mercury through their diets, which incorporate wild foods from these ecosystems.

- Because of large geographic differences in the availability of wild foods and sources of mercury exposure in some northern regions, more locationspecific information is needed to guide health promotion activities.

- Prevalent food insecurity and nutritional concerns can conflict with efforts to reduce mercury exposure in northern communities; patient counselling efforts around mercury exposure thus require a more nuanced and interdisciplinary approach.

- A large body of Canadian and international evidence documents adverse neurodevelopmental outcomes in children exposed prenatally to mercury.

- The evidence base that addresses the health effects associated with longterm postnatal mercury exposure in both children and adults is limited. 


\section{Box 1: Evidence used in this review}

We searched Embase, MEDLINE, Scopus and Google Scholar from 1994 to 2015 for English- and French-language epidemiologic studies conducted in Canada using the following search terms: "mercury" or "methylmercury," and "Canada," "Nunavik," "Nunavut," "Northwest Territories," "Yukon," "Inuit," "Cree," "Dene," "Metis," "First Nations," "indigenous," "Aboriginal" and "fishermen." We conducted a cited reference search on all review articles on the topic. In addition, we reviewed books and technical reports from the National Academy of Sciences, the Arctic Monitoring and Assessment Programme and the World Health Organization.

Prospective longitudinal cohort study designs provide the highest quality evidence for examining mercury-related health outcomes in humans, because experimental studies are not ethical. In Canada, the Nunavik Child Development Study (NCDS) ${ }^{8}$ is the first long-term prospective birth cohort study examining the growth, developmental and behavioural effects of exposure to mercury and other environmental contaminants. The Maternal-Infant Research on Environmental Chemicals (MIREC) study, which began in 2008 in 10 Canadian cities, followed infants to 6 months of age; ${ }^{9}$ the results are being published. Most other Canadian research on prenatal and postnatal mercury exposure is cross-sectional in design. Therefore, we prioritized the NCDS findings. Because of limited longitudinal studies in Canada, we corroborated the NCDS and MIREC findings (the results of which are still being published) with results from other birth cohorts that are considered critical epidemiologic studies in the area. ${ }^{10}$ When comparative longitudinal studies were lacking, we also examined well-known cross-sectional research from outside of Canada. For all exposure groups, most Canadian epidemiologic research on mercuryrelated health effects originates from northern Quebec. delivery. ${ }^{15}$ Breast milk may contain mercury, but because the metal is not lipophilic, infant exposure from breastfeeding is negligible compared with fetal exposure. ${ }^{15}$

Although mercury exposure is a global health issue, ${ }^{10}$ putting any population that consumes large amounts of fish or marine mammals at risk, people in northern Canadian communities may have higher blood mercury levels compared with other populations (Table 1), depending on the types and frequency of wild foods consumed.

Not all wild foods are equal. Although most are low in mercury $(\leq 0.2 \mu \mathrm{g} / \mathrm{g})$, flesh from longlived top predators, such as beluga whales, can accumulate very high mercury concentrations $(>1.0 \mu \mathrm{g} / \mathrm{g}) .{ }^{11,20}$ Freshwater predatory fish, including lake trout, sauger, walleye and northern pike, contain highly variable mercury concentrations depending on the fish's age and characteristics of the local ecosystem. ${ }^{13}$ Box $2^{13,21}$ shows calculations for consumption recommendations for fish with different levels of mercury concentration, according to Health Canada's provisional tolerable daily intake of mercury. ${ }^{21}$ These calculations highlight that the local composition of diet substantially contributes to mercury exposure;

Table 1: Blood mercury concentrations in select Canadian surveys of women of child-bearing age and children

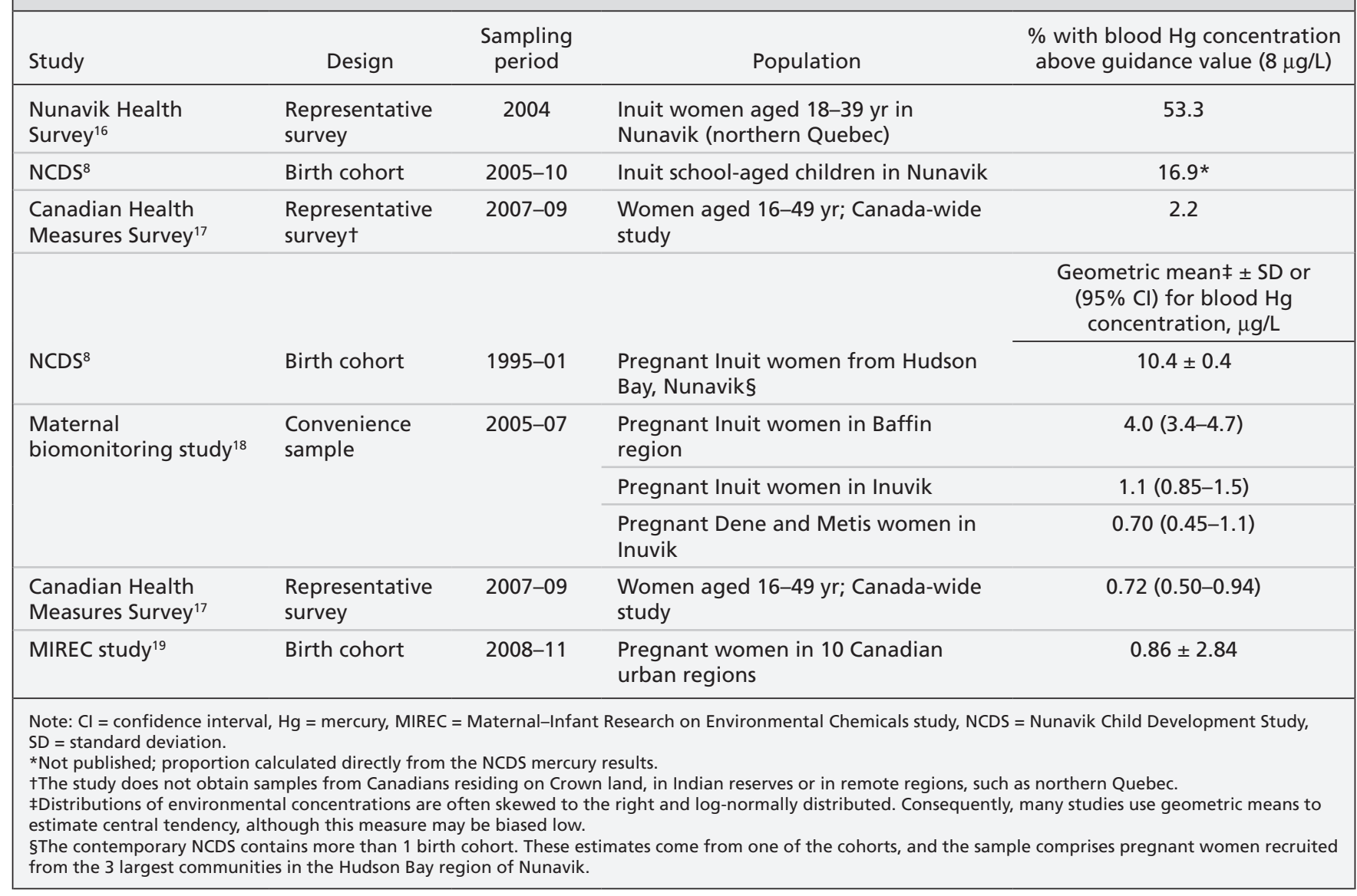


therefore, it is not possible to calculate a general safe level for fish consumption.

Box 3 lists governmental websites with useful information about mercury levels in food, including advisories about freshwater fish consumption from the Government of Quebec. However, more location-specific resources are needed, especially in northern Canada, where there are substantial data gaps. ${ }^{13}$

\section{What is known of the health effects of dietary mercury exposure?}

Two clusters of organic mercury poisoning, in Japan and Iraq, constitute the basis of our knowledge of clinical symptomology in humans. ${ }^{22,23}$ Symptoms of the poisoning and histopathologic changes occurred primarily in the central nervous system. They included sensory impairment of the extremities, constriction of the visual field, cerebellar ataxia, hearing and visual loss, muscle weakness, tremor, cognitive deterioration and death. ${ }^{22,23}$ Among children in Japan exposed prenatally to mercury, the incidence of intellectual disability and cerebral palsy increased substantially. ${ }^{10}$ The incidence of cerebral palsy among children with congenital Minimata disease was 9\% of 188 births in villages affected by the poisoning in Japan compared with a national incidence of $0.2 \%-2.3 \% .^{10}$ Also, even among those without known congenital Minimata disease, the prevalence of intellectual disability among children born between 1955 and 1958 in the contaminated area was $29 \% .{ }^{10}$ Although less well documented, mercury poisoning may have occurred in Canada, such as in Grassy Narrows during the 1970s. ${ }^{24}$ Manifestations of mercury intoxication are often nonspecific, vary between individuals and require assessment by an expert (medical toxicologist or neurologist). ${ }^{25}$

In the last 30 years, research has focused on the subclinical effects of mercury in populations habitually exposed to lower levels of mercury than observed in Japan and Iraq. Most work is on the effects of prenatal exposure in children. In Canada, the Nunavik Child Development Study (NCDS) provides the highest quality longitudinal results on these effects (Box 4). ${ }^{8}$

\section{What are the effects of prenatal mercury exposure in children?}

Evidence from Canada and abroad strongly indicates that prenatal, and possibly postnatal, expo- sure to mercury negatively affects multiple domains of child development. The NCDS has looked extensively at the neurodevelopmental effects of prenatal exposure to mercury through maternal diet. The findings have included poorer early high-contrast visual processing ${ }^{26}$ changes in attentional processing of sensory information, ${ }^{27}$ poorer immediate memory and long-term recollection memory, ${ }^{28}$ increased prevalence of symptoms of attention-deficit/hyperactivity disorder in the classroom, ${ }^{29}$ poorer estimated intellectual quotient and increased risk of intellectual disability. ${ }^{30}$ These results are corroborated by findings from birth cohorts in the Faroe Islands and New Zealand. . $^{31,32}$

Increased exposure to mercury during pregnancy might affect obstetric and perinatal outcomes. According to the NCDS, moderate to ele-

\section{Box 2: How mercury levels in fish translate into fish consumption} guidelines

Health Canada's recommended provisional tolerable daily intake (pTDI) of mercury:21

- Adults: $0.47 \mu \mathrm{g} / \mathrm{kg}$ body weight per day

- Women of child-bearing age and children: $0.2 \mu \mathrm{g} / \mathrm{kg}$ body weight per day* A person's probable daily intake of mercury (in $\mu \mathrm{g} / \mathrm{kg}$ weight per day) can be calculated with the following formula: [fish portion $(\mathrm{g}) \times$ frequency of consumption (times $/ \mathrm{d}) \times$ mercury in fish $(\mu \mathrm{g} / \mathrm{g})] \div$ body weight $(\mathrm{kg})$

For example, a $60-\mathrm{kg}$ pregnant woman can eat $150 \mathrm{~g}$ of a given fish species at the following maximum frequencies to avoid exceeding the recommended pTDI:

Fish low in mercury $(0.2 \mu \mathrm{g} / \mathrm{g})$

- No. times $/ d=0.40$

- No. times $/ w k=2.8$

- No. times $/ \mathrm{mo}=12.4$

Fish high in mercury $(0.5 \mu \mathrm{g} / \mathrm{g})$

- No. times $/ d=0.16$

- No. times/wk = 1.1

- No. times $/ \mathrm{mo}=5.0$

Fish very high in mercury $(1.0 \mu \mathrm{g} / \mathrm{g})$

- No. times $/ d=0.08$

- No. times $/ w k=0.6$

- No. times $/ \mathrm{mo}=2.5$

Fish extremely high in mercury $(4.0 \mu \mathrm{g} / \mathrm{g})$

- No. times $/ d=0.02$

- No. times/wk =0.1

- No. times $/ \mathrm{mo}=0.6$

As a general rule, because fish is important to good health, practitioners in northern Canada may consider counselling their patients with the following: "Eat wild foods, including smaller fish and fish that don't eat other fish. When possible, eat less larger fish that eat other fish."

Examples of piscivorous fish with elevated median mercury concentrations that are relevant to northern Canada include lake trout, walleye and northern pike. In contrast, brook trout, rainbow trout and lake whitefish ${ }^{13}$ tend to have much lower median mercury concentrations and are appropriate substitutes.

*This recommended pTDI is based on $10 \mu \mathrm{g} / \mathrm{g}$ in maternal hair (equivalent to $200 \mathrm{nmol} / \mathrm{L}$ or $40 \mu \mathrm{g} / \mathrm{L}$ in blood) as the approximate threshold for adverse neurodevelopmental outcomes with a fivefold uncertainty factor to account for variability between individuals. ${ }^{21}$ 
vated cord blood mercury levels were associated with a shorter gestation (by about eight days) compared with relatively low cord blood levels. Shortened gestation, in turn, was associated with reduced fetal growth. ${ }^{33}$ Similar results were reported in other prospective birth cohorts ${ }^{34}$ including the Canadian Maternal-Infant Research on Environmental Chemicals study. ${ }^{35}$

Concerning postnatal exposure to mercury, the NCDS observed an association with fine neuromotor function ${ }^{36}$ and the functional integrity of the visual system in five-year-old children. ${ }^{37}$ Postnatal exposure to mercury measured at age 11 was associated with decreased heart rate variability, a risk factor for cardiovascular disease in adults. ${ }^{38}$ Similar results were observed in the first Faroe Islands birth cohort, but it was not possible to distinguish the effects of prenatal from postnatal exposure because of high intercorrelation in mercury exposure at different developmental stages. ${ }^{39}$ Overall, because mercury-induced damage is enduring, these findings underscore the importance of preventing unnecessary exposure in women of child-bearing age through counselling on dietary adjustment.

\section{What are the effects of long-term mercury exposure in adults?}

Although high mercury levels $(>100 \mu \mathrm{g} / \mathrm{L}$ in blood) have occasionally been reported in Cana-

\section{Box 3: Resources for clinicians and patients about mercury in food} and the environment

- Questions and answers about mercury in fish from Health Canada: www. hc-sc.gc.ca/fn-an/securit/chem-chim/environ/mercur/merc_fish_qa-poisson _qr-eng.php

- Advice from Health Canada on making informed choices about fish consumption: www.hc-sc.gc.ca/fn-an/securit/chem-chim/environ/mercur/ cons-adv-etud-eng.php

- Fish consumption advisories posted by Environment and Climate Change Canada: www.ec.gc.ca/mercure-mercury/default. asp?lang=En\&n=DCBE5083-1

- Guide to eating Quebec sport fish from the Government of Quebec [in French]: www.mddelcc.gouv.qc.ca/eau/guide

\section{Box 4: Nunavik Child Development Study (NCDS)}

Elevated levels of mercury have been documented among Inuit from Nunavik, a region in northern Quebec. ${ }^{8}$ The NCDS is a longitudinal study that has been following a sample of 294 mother-child dyads from the region who were recruited between 1994 and 2001. The primary objective of the study is to document the growth, developmental and behavioural effects of pre- and postnatal exposure to environmental contaminants, including mercury. These dyads have been sampled on multiple occasions, most recently between 2005 and 2010 when the children were about 11 years old. A follow-up of the cohort is underway to test youth aged 16 to 20 years. Globally, there are a handful of similar long-term birth cohorts, including the influential 1986-88 Faroe Islands cohort of 1022 singleton births followed at ages 7, 14 and 23 years. dian adults since the 1970s, mercury-induced signs and symptoms have never been comprehensively studied. Consequently, it is virtually impossible to establish diagnostic criteria for mercury intoxication at exposure levels relevant to northern Canada. Moreover, the evidence base for the health effects of long-term mercury exposure in Canadian adults is limited in scope and methodology. For example, among 135 Quebec Cree adults less than 40 years old, tremor was significantly associated with increasing mercury concentrations when measured by a general clinical examination but not by a specialized neurologic examination. ${ }^{40}$ The study was the result of a lawsuit, which may have compromised internal validity because participants with symptoms may have self-selected into the study. In a crosssectional study with a control group of nonexposed Japanese residents, First Nations adults from Grassy Narrows, Ontario, exhibited neurologic symptoms consistent with mercury poisoning, but the study lacked biomarker data of actual mercury exposure. ${ }^{41}$ Other cross-sectional studies conducted outside of Canada have also documented neurologic abnormalities in fisheating populations with comparable mercury exposure levels. ${ }^{42}$

In contrast to children, in whom the developing brain is a critical target of mercury toxicity, the cardiovascular system may be most sensitive in adults. ${ }^{1}$ Representative surveys of Nunavik Inuit and Cree adults documented associations between increasing blood mercury concentrations and risk markers for cardiovascular disease. ${ }^{43,44}$ Although the studies used crosssectional designs and had low response rates $(\leq 50 \%)$, they had large samples $(>600)$ and adjusted extensively for confounders. ${ }^{43,44}$ It is possible that chronic conditions influence mercury metabolism and excretion, and thus affect exposure concentrations observed in crosssectional studies (e.g., reverse causality). In addition, cross-sectional studies cannot determine whether the observed mercury-induced cardiovascular damage occurred prenatally or postnatally. Two well-conducted nested case-control studies analyzing data from large prospective US cohorts found no association between mercury exposure and hypertension, nonfatal myocardial infarction, coronary artery disease or stroke in adults free of cardiovascular disease at baseline; however, exposure levels in these cohorts were lower than those typically observed in northern Canada. ${ }^{45,46}$ In the absence of prospective studies among adults with greater exposure levels, it may be justifiable to advise people with elevated cardiovascular risk to reduce mercury exposure as a precaution. 


\section{How should mercury exposure be assessed?}

Biological specimens that can be used to measure the body burden of mercury are summarized in Table 2. Blood and hair are considered optimal for assessing dietary mercury exposure in adults. Maternal blood and hair sampled during early pregnancy, and cord blood at delivery, are gold standards for measuring prenatal exposure.

In 2010, Legrand and colleagues ${ }^{2}$ calculated mercury thresholds of concern and appropriate clinical actions depending on an individual's age and sex. In Table 3, we have adapted these to include Quebec-specific thresholds and other considerations for geographically remote contexts.

\section{How can dietary counselling be tailored for residents in northern}

\section{Canada?}

Mercury exposure is one of many health concerns facing northern Canadian communities. Counselling to reduce exposure must recognize and address wider food security issues and nutritional challenges, or it will unlikely be effective. Linked with a rapid transition from wild foods to a Western diet, food quality and nutrient intakes have declined in many indigenous communities, which has contributed to increasing rates of chronic diseases and obesity among adults. ${ }^{50}$ Many northern communities also experience exceptional levels of food insecurity, with most people in some communities compromising the quantity and quality of foods they consume. ${ }^{6}$ These factors complicate counselling strategies, especially during pregnancy when the fetus is most vulnerable to mercury exposure. In addition, past efforts to reduce dietary mercury exposure have frightened and confused some communities about wild foods, ${ }^{51}$ even though for many, procuring, eating and sharing wild foods promotes a healthy spirit, mind and body. ${ }^{52}$ Wild foods are also nutritionally rich in proteins, vitamins, minerals and phytochemicals. ${ }^{16}$

In the following sections, we provide an overview of food security and nutritional considerations related to wild foods and mercury exposure during pregnancy. Specifically, omega-3 fatty acids, selenium and, more recently, iron have been the focus of extensive epidemiologic research into the appropriate interpretation of many health out-

Table 2: Summary of recommended biological specimens to evaluate dietary mercury exposure

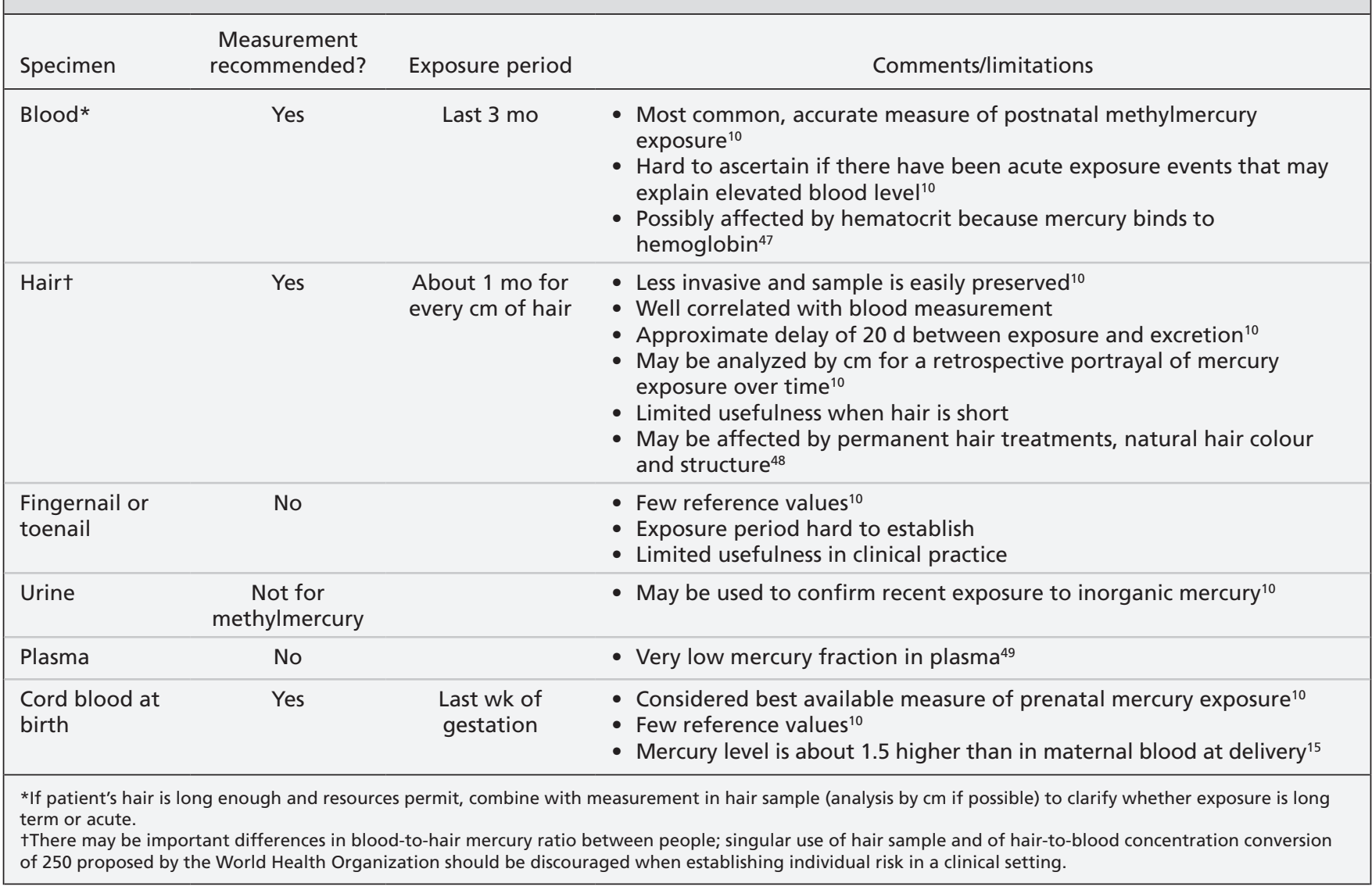


comes associated with mercury exposure, because these nutrients may confound observed associations or biochemically interact with the contaminant to influence toxicity. ${ }^{53-55}$ Because our objective is to highlight specific health care concerns often concomitant with elevated mercury exposure in northern communities, we have not reviewed all research on mercury-nutrient interactions. Instead, we focus on food security and nutritional concerns that are especially relevant to northern Canada and for which there is a substantial evidence base upon which guidance to health professionals can be based. Our overarching goal is to improve providers' messaging to patients about dietary mercury exposure.

\section{Food security and fetal sensitivity to mercury}

A sudden change in food intake during pregnancy might increase fetal sensitivity to toxic substances,

Table 3: Health Canada and Quebec mercury guidance values and recommended actions ${ }^{2}$

\begin{tabular}{|c|c|c|c|}
\hline \multirow[b]{2}{*}{ Group } & \multicolumn{2}{|c|}{ Total mercury level } & \multirow[b]{2}{*}{ Recommended actions } \\
\hline & In blood & In hair & \\
\hline \multirow{4}{*}{$\begin{array}{l}\text { - Women of child-bearing } \\
\text { age } \\
\text { - Children }<18 \mathrm{yr}\end{array}$} & $\begin{array}{l}<8 \mu \mathrm{g} / \mathrm{L} \\
(<40 \mathrm{nmol} / \mathrm{L})\end{array}$ & $<2 \mu \mathrm{g} / \mathrm{g}$ & - No follow-up required \\
\hline & $\begin{array}{l}8-40 \mu \mathrm{g} / \mathrm{L} \\
(>40-200 \mathrm{nmol} / \mathrm{L})\end{array}$ & $>2-10 \mu \mathrm{g} / \mathrm{g}$ & $\begin{array}{l}\text { - Repeat blood/hair test immediately in pregnant women; } \\
\text { otherwise repeat in 3-6 mo } \\
\text { - Identify dietary sources of exposure and provide dietary } \\
\text { advice, taking into account social importance of wild foods } \\
\text { - If food insecurity or micronutrient deficiency is a concern, } \\
\text { consult with nutritionist or dietitian for low-mercury, } \\
\text { high-nutrient food options }\end{array}$ \\
\hline & $\begin{array}{l}>40-100 \mu \mathrm{g} / \mathrm{L} \\
(>200-500 \mathrm{nmol} / \mathrm{L})\end{array}$ & $>10-25 \mu \mathrm{g} / \mathrm{g}$ & $\begin{array}{l}\text { - Repeat blood/hair test immediately } \\
\text { - Identify dietary sources of exposure and provide dietary } \\
\text { advice, taking into account social importance of wild foods } \\
\text { - If food insecurity or micronutrient deficiency is a concern, } \\
\text { consult with nutritionist or dietitian for low-mercury, } \\
\text { high-nutrient food options }\end{array}$ \\
\hline & $\begin{array}{l}>100 \mu \mathrm{g} / \mathrm{L} \\
(>500 \mathrm{nmol} / \mathrm{L})\end{array}$ & $>25 \mu \mathrm{g} / \mathrm{g}$ & $\begin{array}{l}\text { - Repeat blood/hair test immediately } \\
\text { - Request mercury speciation in whole blood to discriminate } \\
\text { dietary methylmercury from inorganic mercury exposure } \\
\text { - If inorganic mercury, identify environmental sources of } \\
\text { exposure and seek solutions with patient to eliminate } \\
\text { exposure } \\
\text { - If methylmercury, identify dietary sources of exposure and } \\
\text { provide dietary advice } \\
\text { - If accompanied by symptoms of mercury exposure, refer } \\
\text { patient to an expert (medical toxicologist or neurologist) }\end{array}$ \\
\hline \multirow{3}{*}{$\begin{array}{l}\text { - Women > child-bearing } \\
\text { age } \\
\text { - Men > } 18 \mathrm{yr}\end{array}$} & $\begin{array}{l}<20 \mu \mathrm{g} / \mathrm{L} \\
(<100 \mathrm{nmol} / \mathrm{L})\end{array}$ & $<5 \mu \mathrm{g} / \mathrm{g}$ & - No follow-up required \\
\hline & $\begin{array}{l}20-100 \mu \mathrm{g} / \mathrm{L} \\
(100-500 \mathrm{nmol} / \mathrm{L})\end{array}$ & $>5-25 \mu \mathrm{g} / \mathrm{g}$ & $\begin{array}{l}\text { - Repeat blood/hair test in 3-6 mo } \\
\text { - Identify dietary sources of exposure and provide dietary } \\
\text { advice, taking into account social importance of wild foods } \\
\text { - If food insecurity or micronutrient deficiency is a concern, } \\
\text { consult with nutritionist or dietitian for low-mercury, } \\
\text { high-nutrient food options }\end{array}$ \\
\hline & $\begin{array}{l}>100 \mu \mathrm{g} / \mathrm{L} \\
(>500 \mathrm{nmol} / \mathrm{L})\end{array}$ & $>25 \mu \mathrm{g} / \mathrm{g}$ & $\begin{array}{l}\text { - Repeat blood/hair test immediately } \\
\text { - Request mercury speciation in whole blood to discriminate } \\
\text { dietary methylmercury from inorganic mercury exposure } \\
\text { - If inorganic mercury, identify environmental sources of } \\
\text { exposure and seek solutions with patient to eliminate } \\
\text { exposure } \\
\text { - If methylmercury, identify dietary sources of exposure and } \\
\text { provide dietary advice } \\
\text { - If accompanied by symptoms of mercury exposure, refer } \\
\text { patient to an expert (medical toxicologist or neurologist) }\end{array}$ \\
\hline - All groups (Quebec only) & $\begin{array}{l}\geq 12 \mu \mathrm{g} / \mathrm{L} \\
(\geq 60 \mathrm{nmol} / \mathrm{L})\end{array}$ & $\geq 3 \mu \mathrm{g} / \mathrm{g}$ & $\begin{array}{l}\text { Test result must be declared to regional public health } \\
\text { authority (consult steps to be taken at www.msss.gouv.qc. } \\
\text { ca/professionnels/mado/demarche_medecins.php) }\end{array}$ \\
\hline
\end{tabular}


including mercury. ${ }^{56}$ One population-based crosssectional study in Bangladesh concluded that women and children were more at risk than men for both toxic metal exposure and micronutrient deficiency. ${ }^{57}$ To our knowledge, no epidemiologic research in Canada and elsewhere has investigated whether mercury toxicity differs according to food security status, sex, general nutrition or micronutrient deficiency. Health advice to women of childbearing age about mercury should factor in the wider context of food insecurity by avoiding messages that scare families away from wild foods low in mercury.

\section{Omega-3 fatty acids, mercury and health outcomes}

Omega-3 fatty acids from the mother's diet are essential components of membrane phospholipids and are deposited to the fetus' central nervous system in relatively large quantities during the last trimester of pregnancy and first months of life.$^{58}$ Fatty acids in fish and seafood negatively confound associations between mercury and neurotoxicity. ${ }^{53}$ In Nunavik, greater intake of omega-3 fatty acids during the last trimester of pregnancy is associated with better neurophysiologic and neurobehavioural outcomes. ${ }^{28}$ The benefits of prenatal exposure to omega- 3 fatty acids are maintained throughout childhood $^{28}$ and reduce sensitivity to outcomes of mercury exposure, such as intellectual disability. ${ }^{30}$

Although omega-3 fatty acids may not counteract the toxic effects of mercury, they have been positively associated with many of the same health outcomes with which mercury exposure has been negatively associated. Fatty fish (e.g., salmon, sardines and herring) and marine mammal fat are high in omega- 3 fatty acids and generally low in mercury, and their consumption can be encouraged during pregnancy.

\section{Selenium-mercury interactions}

Experimental and cross-sectional studies suggest toxicokinetic interactions between selenium and mercury, with selenium reducing the reproductive, neurologic and cardiovascular toxic effects associated with mercury exposure. ${ }^{43,55}$

Such findings are unconfirmed in epidemiologic studies from northern Canada. But if true, this would raise concerns of even greater toxic effects from mercury in certain northern communities with previously high selenium intakes from wild foods ${ }^{16}$ that are now rapidly being exchanged for Western diets with lower selenium concentrations.

\section{Iron deficiency and mercury exposure during pregnancy}

The prevalence of iron deficiency is high in some northern communities with elevated food insecurity or ongoing nutritional transition. ${ }^{59}$ Positive correlations between iron stores and blood mercury levels have been documented; 59 methylmercury is known to accumulate in red blood cells and bind to hemoglobin. ${ }^{47}$ In Nunavik, the correlation was attributed to general consumption of wild foods, because many wild foods have elevated levels of bioavailable iron..$^{59}$ Both iron deficiency and prenatal exposure to mercury negatively affect children's brain development, potentially confounding these associations in populations where both are high. ${ }^{54}$

Dietary advice to reduce mercury exposure should likewise not increase the risk of iron deficiency during pregnancy by scaring women away from iron-rich wild foods, especially terrestrial species that are low in mercury.

\section{Conclusion}

The Minamata Convention on Mercury, a global treaty to protect humans and the environment from adverse effects of mercury, was approved in January 2013. It includes a ban on new mercury mines, phasing out of old ones, air emissions controls, and regulations for international artisanal and small-scale gold mining. If successful, long-term anthropogenic emissions of mercury may decline, reducing global environmental concentrations.

For now, we expect communities that frequently consume predatory fish or marine mammals to have elevated mercury exposure. It is important for clinicians to be clear on the potential risks of mercury exposure, the complexity of the underlying epidemiologic data and how to counsel, in a culturally sensitive manner, patients in communities where mercury exposure may be a concern. Gaps in knowledge are summarized in Box 5. Regionally specific sources of information on popular wild foods and their nutritional and contaminant properties that are understandable to health care providers and their patients are required.

\section{Box 5: Gaps in knowledge}

- More location-specific tools are needed to guide health promotion activities in northern Canada, given the large geographic variation in mercury concentrations in wild foods.

- Prospective studies are needed of adverse health effects from long-term exposure to mercury in adults, especially in communities with elevated mercury levels.

- Research is needed that simultaneously examines food security, malnutrition (including obesity), micronutrient deficiencies and mercury toxicity. 


\section{References}

1. Karagas MR, Choi AL, Oken E, et al. Evidence on the human health effects of low-level methylmercury exposure. Environ Health Perspect 2012;120:799-806.

2. Legrand M, Feeley M, Tikhonov C, et al. Methylmercury blood guidance values for Canada. Can J Public Health 2010;101:28-31.

3. Koren G, Bend JR. Fish consumption in pregnancy and fetal risks of methylmercury toxicity. Can Fam Physician 2010;56:1001-2

4. Brodkin E, Copes R, Mattman A, et al. Lead and mercury exposures: interpretation and action. CMAJ 2007;176:59-63.

5. AMAP assessment 2009: human health in the Arctic. Oslo: Arctic Monitoring and Assessment Programme; 2009.

6. Huet C, Rosol R, Egeland GM. The prevalence of food insecurity is high and the diet quality poor in Inuit communities. J Nutr 2012;142:541-7.

7. Kuhnlein HV, Receveur O, Soueida R, et al. Arctic indigenous peoples experience the nutrition transition with changing dietary patterns and obesity. J Nutr 2004; 134:1447-53.

8. Muckle G, Ayotte P, Dewailly EE, et al. Prenatal exposure of the northern Quebec Inuit infants to environmental contaminants. Environ Health Perspect 2001;109:1291-9.

9. Arbuckle TE, Fraser WD, Fisher M, et al. Cohort profile: the Maternal-Infant Research on Environmental Chemicals research platform. Paediatr Perinat Epidemiol 2013;27:415-25.

10. National Research Council. Toxicological effects of methylmercury. Washington (DC): National Academy Press; 2000.

11. AMAP assessment 2011: mercury in the Arctic. Oslo: Arctic Monitoring and Assessment Programme; 2011.

12. Clarkson TW. The three modern faces of mercury. Environ Health Perspect 2002;110(Suppl 1):11-23.

13. Depew DC, Burgess NM, Anderson MR, et al. An overview of mercury concentrations in freshwater fish species: a national fish mercury dataset for Canada. Can J Fish Aquat Sci 2013;70:436-51.

14. Kirk JL, Muir DC, Gleason A, et al. Atmospheric deposition of mercury and methylmercury to landscapes and waterbodies of the Athabasca oil sands region. Environ Sci Technol 2014;48:7374-83.

15. Björnberg KA, Vahter M, Berglund B, et al. Transport of methylmercury and inorganic mercury to the fetus and breast-fed infant. Environ Health Perspect 2005;113:1381-5.

16. Lemire M, Kwan M, Laouan-Sidi E, et al. Local country food sources of methylmercury, selenium and omega- 3 fatty acids in Nunavik, Northern Quebec. Sci Total Environ 2015;509:248-59.

17. Lye E, Legrand M, Clarke J, et al. Blood total mercury concentrations in the Canadian population: Canadian Health Measures Survey cycle 1, 2007-2009. Can J Public Health 2013;104:e246-51.

18. Curren MS, Liang CL, Davis K, et al. Assessing determinants of maternal blood concentrations for persistent organic pollutants and metals in the eastern and western Canadian Arctic. Sci Total Environ 2015;527-528:150-8

19. Ashley-Martin J, Dodds L, Arbuckle TE, et al. Maternal blood metal levels and fetal markers of metabolic function. Environ Res 2015;136:27-34.

20. Mercury in fish - questions and answers. Ottawa: Health Canada; 2011. Available: www.hc-sc.gc.ca/fn-an/securit/chem -chim/environ/mercur/merc_fish_qa-poisson_qr-eng.php (accessed 2014 July 7)

21. Human health risk assessment of mercury in fish and health benefits of fish consumption. Ottawa: Health Canada; 2007. Available: www.hc-sc.gc.ca/fn-an/pubs/mercur/merc_fish_poisson -eng.php (accessed 2016 Mar. 7).

22. Bakir F, Damluji SF, Amin-Zaki L, et al. Methylmercury poisoning in Iraq. Science 1973;181:230-41.

23. Harada M. Congenital Minamata disease: intrauterine methylmercury poisoning. Teratology 1978;18:285-8.

24. Shephard DA. Methyl mercury poisoning in Canada. Can Med Assoc J 1976;114:463-72.

25. Silbernagel SM, Carpenter DO, Gilbert SG, et al. Recognizing and preventing overexposure to methylmercury from fish and seafood consumption: information for physicians. J Toxicol 2011; 2011:983072.

26. Ethier AA, Muckle G, Bastien C, et al. Effects of environmental contaminant exposure on visual brain development: a prospective electrophysiological study in school-aged children. Neurotoxicology 2012;33:1075-85.

27. Boucher O, Bastien CH, Saint-Amour D, et al. Prenatal exposure to methylmercury and PCBs affects distinct stages of information processing: an event-related potential study with Inuit children. Neurotoxicology 2010;31:373-84.

28. Boucher O, Burden MJ, Muckle G, et al. Neurophysiologic and neurobehavioral evidence of beneficial effects of prenatal omega- 3 fatty acid intake on memory function at school age. Am J Clin Nutr 2011;93:1025-37.

29. Boucher O, Jacobson SW, Plusquellec P, et al. Prenatal methylmercury, postnatal lead exposure, and evidence of attention deficit/ hyperactivity disorder among Inuit children in Arctic Quebec. Environ Health Perspect 2012;120:1456-61.

30. Jacobson JL, Muckle G, Ayotte P, et al. Relation of prenatal methylmercury exposure from environmental sources to childhood IQ. Environ Health Perspect 2015;123:827-33.

31. Grandjean P, Weihe P, White RF, et al. Cognitive deficit in 7-year-old children with prenatal exposure to methylmercury. Neurotoxicol Teratol 1997;19:417-28.

32. Crump KS, Kjellstrom T, Shipp AM, et al. Influence of prenatal mercury exposure upon scholastic and psychological test performance: benchmark analysis of a New Zealand cohort. Risk Anal 1998;18:701-13.

33. Dallaire R, Dewailly E, Ayotte P, et al. Exposure to organochlorines and mercury through fish and marine mammal consumption: associations with growth and duration of gestation among Inuit newborns. Environ Int 2013;54:85-91.

34. Xue F, Holzman C, Rahbar MH, et al. Maternal fish consumption, mercury levels, and risk of preterm delivery. Environ Health Perspect 2007;115:42-7.

35. Thomas S, Arbuckle TE, Fisher M, et al. Metals exposure and risk of small-for-gestational age birth in a Canadian birth cohort: the MIREC study. Environ Res 2015;140:430-9.

36. Després C, Beuter A, Richer F, et al. Neuromotor functions in Inuit preschool children exposed to $\mathrm{Pb}, \mathrm{PCBs}$, and $\mathrm{Hg}$. Neurotoxicol Teratol 2005;27:245-57.

37. Saint-Amour D, Roy MS, Bastien C, et al. Alterations of visual evoked potentials in preschool Inuit children exposed to methylmercury and polychlorinated biphenyls from a marine diet. Neurotoxicology 2006;27:567-78

38. Valera B, Muckle G, Poirier P, et al. Cardiac autonomic activity and blood pressure among Inuit children exposed to mercury. Neurotoxicology 2012;33:1067-74.

39. Grandjean P, Weihe P, Debes F, et al. Neurotoxicity from prenatal and postnatal exposure to methylmercury. Neurotoxicol Teratol 2014:43:39-44

40. Auger N, Kofman O, Kosatsky T, et al. Low-level methylmercury exposure as a risk factor for neurologic abnormalities in adults. Neurotoxicology 2005;26:149-57.

41. Takaoka S, Fujino T, Hotta N, et al. Signs and symptoms of methylmercury contamination in a First Nations community in Northwestern Ontario, Canada. Sci Total Environ 2014;468-469:950-7.

42. Lebel J, Mergler D, Branches F, et al. Neurotoxic effects of lowlevel methylmercury contamination in the Amazonian Basin. Environ Res 1998;79:20-32.

43. Valera B, Dewailly E, Poirier P. Environmental mercury exposure and blood pressure among Nunavik Inuit adults. Hypertension 2009;54:981-6.

44. Valera B, Dewailly E, Poirier P. Impact of mercury exposure on blood pressure and cardiac autonomic activity among Cree adults (James Bay, Quebec, Canada). Environ Res 2011;111:1265-70.

45. Mozaffarian D, Shi P, Morris JS, et al. Mercury exposure and risk of hypertension in US men and women in 2 prospective cohorts. Hypertension 2012;60:645-52.

46. Mozaffarian D, Shi P, Morris JS, et al. Mercury exposure and risk of cardiovascular disease in two U.S. cohorts. $N$ Engl J Med 2011;364:1116-25.

47. Kim BM, Choi AL, Ha EH, et al. Effect of hemoglobin adjustment on the precision of mercury concentrations in maternal and cord blood. Environ Res 2014;132:407-12.

48. Grandjean P, Budtz-Jorgensen E. Total imprecision of exposure biomarkers: implications for calculating exposure limits. Am J Ind Med 2007;50:712-9.

49. Nuttall KL. Interpretting mercury in blood and urine of individual patients. Ann Clin Lab Sci 2004 Summer;34:235-50.

50. Gionet L. Roshanafshar S. Select health indicators of First Nations people living off reserve, Métis and Inuit. Ottawa: Statistics Canada. Cat no. 82-624-X. Available: www.statcan.gc.ca/pub/82-624 -x/2013001/article/11763-eng.htm (accessed 2015 Aug. 12).

51. Furgal C, Powell S, Myer H. Digesting the message about contaminants and country foods in the Canadian North: a review and recommendations for future research and action. Arctic 2005;58:103-14

52. Inuit and the right to food: submission to the United Nations Special Rapporteur on the Right to Food for the Official Country Mission to Canada. Ottawa: Inuit Tapiriit Kanatami and Inuit Circumpolar Council; 2012. Available: www.inuitcircumpolar. com/uploads/3/0/5/4/30542564/icc.itk.inuit_and_the_right_to _food-for_un_rapporteur_on_the_right_to_food.pdf (accessed 2013 Sept. 13).

53. Choi AL, Mogensen UB, Bjerve KS, et al. Negative confounding by essential fatty acids in methylmercury neurotoxicity associations. Neurotoxicol Teratol 2014;42:85-92.

54. Fonseca Mde F, De Souza Hacon S, Granjean P, et al. Iron status as a covariate in methylmercury-associated neurotoxicity risk. Chemosphere 2014;100:89-96. 
55. Khan MA, Wang F. Mercury-selenium compounds and their toxicological significance: toward a molecular understanding of the mercury-selenium antagonism. Environ toxicology chem 2009;28:1567-77

56. Fox DA, Grandjean P, de Groot D, et al. Developmental origins of adult diseases and neurotoxicity: epidemiological and experimental studies. Neurotoxicology 2012;33:810-6.

57. Berglund M, Lindberg AL, Rahman M, et al. Gender and age differences in mixed metal exposure and urinary excretion. Environ Res 2011;111:1271-9.

58. Innis SM. Essential fatty acids in growth and development. Prog Lipid Res 1991;30:39-103.

59. Plante $\mathrm{C}$, Blanchet $\mathrm{C}$, Rochette $\mathrm{L}$, et al. Prevalence of anemia among Inuit women in Nunavik, Canada. Int J Circumpolar Health 2011;70:154-65.

Affiliations: Office of Public Health Studies (Pirkle), University of Hawaii at Manoa, Honolulu; École de psychologie (Muckle), Université Laval, Laval, Que.; Axe santé des populations et pratiques optimales en santé (Lemire, Muckle), Centre de recherche du CHU de Québec, Québec, Que.

Contributors: Catherine Pirkle and Melanie Lemire contributed equally to the conception and outline of the manuscript. Catherine Pirkle reviewed the literature, with substantial input from Melanie Lemire and Gina Muckle. Catherine Pirkle drafted the first version of the manuscript All of the authors contributed to the interpretation of the literature discussed in the article and to the critical revisions of subsequent drafts, approved the final version of the manuscript to be published and agreed to act as guarantors of the work.
Acknowledgement: Catherine Pirkle was supported by a postdoctoral fellowship award from the Institute of Aboriginal Peoples' Health, Canadian Institutes of Health Research, during which much of this work was conducted.

\section{Change of address}

We require 6 to 8 weeks' notice to ensure uninterrupted service. Please send your current mailing label, new address and the effective date of change to:

CMA Member Service Centre 1870 Alta Vista Dr. Ottawa ON K1G 6R7

tel $888855-2555$ or

$613731-8610 \times 2307$

fax $613236-8864$

cmamsc@cma.ca

\begin{tabular}{|c|c|}
\hline $\begin{array}{r}\text { ASSOCIATION } \\
\text { MÉDICALE } \\
\text { CANADIENNE }\end{array}$ & $\begin{array}{l}\text { CANADIAN } \\
\text { MEDICAL } \\
\text { ASSOCIATION }\end{array}$ \\
\hline
\end{tabular}

